ORIGINAL RESEARCH

\title{
Injuries and Illnesses of Big Game Hunters in Western Colorado: A 9-Year Analysis
}

\author{
Allan D. Reishus, MD \\ From the Emergency Department, The Memorial Hospital, Craig, CO (Dr Reishus).

\begin{abstract}
Category 1 Continuing Medical Education credit for physicians is available to Wilderness Medical Society members for this article. Go to www.wemjournal.org to access the instructions and test questions.
\end{abstract}

\begin{abstract}
Objective.-The purpose of this study was to characterize big game hunter visits to a rural hospital's emergency department (ED). Using data collected on fatalities, injuries, and illnesses over a 9-year period, trends were noted and comparisons made to ED visits of alpine skiers, swimmers, and bicyclists. Out-of-hospital hunter fatalities reported by the county coroner's office were also reviewed. Cautionary advice is offered for potential big game hunters and their health care providers.

Methods.- Self-identified hunters were noted in the ED log of a rural Colorado hospital from 1997 to 2005, and injury or illness and outcome were recorded. Additional out-of-hospital mortality data were obtained from the county coroner's office. The estimated total number of big game hunters in the hospital's service area and their average days of hunting were reported by the Colorado Division of Wildlife. The frequencies of hunters' illnesses, injuries, and deaths were calculated.

Results.-A total of 725 ED visits - an average of 80 per year-were recorded. Nearly all visits were in the prime hunting months of September to November. Twenty-seven percent of the hunter ED patients were Colorado residents, and $73 \%$ were from out of state. Forty-five percent of the visits were for trauma, $31 \%$ for medical illnesses, and $24 \%$ were labeled "other." The most common medical visits (105) were for cardiac signs and symptoms, and all of the ED deaths (4) were attributed to cardiac causes. The most common trauma diagnosis was laceration (151), the majority (113) of which came from accidental knife injuries, usually while the hunter was field dressing big game animals. Gunshot wounds $(4,<1 \%)$ were rare. Horse-related injuries to hunters declined while motor vehicleand all-terrain vehicle (ATV)-related injuries increased. The five out-of-hospital deaths were cardiac related (3), motor vehicle related (1), and firearm related (1).

Conclusions.- - Fatal outcomes in big game hunters most commonly resulted from cardiac diseases. Gunshot injuries and mortalities were very low in this population. Knife injuries were common. Hunters and their health care providers should consider a thorough cardiac evaluation prior to big game hunts. Hunter safety instructors should consider teaching aspects of safe knife use. Consideration should be given to requiring and improving ATV driver education.
\end{abstract}

Key words: hunting-related injuries and deaths, Colorado, big game hunting

\section{Introduction}

In the western United States big game hunting for meat and recreation continues to be a popular activity. Hunting may be sedentary, such as when the hunter is hunting from a stand, but it is often quite strenuous. A hunter may intend to sit quietly waiting for game but may sud-

Corresponding author: Allan D. Reishus, MD, Emergency Department, The Memorial Hospital, 785 Russell St, Craig, CO 81625 (e-mail: areishus@amigo.net). denly find himself on a steep mountainside in pursuit of a wounded animal. Elevation in our study area averages around 6500 feet $(2000 \mathrm{~m})$ above sea level, with some areas that are popular for hunting reaching 10000 feet (3000 m). Most big game hunters in this study come from lower elevations. Weather conditions vary from hot and dry in August and September at lower elevations to subzero temperatures and blizzard conditions at higher elevations in later months. Travel to the area is often exhausting for the hunter, and the trip may be preceded 
by days or weeks of busy preparations. Hunters report that their sleep patterns are interrupted and that their diet prior to and during the hunt may be laced with salt and fat. Other hunters report that a prehunt exercise and weight-loss program was planned and then neglected in the rush to fulfill responsibilities at home. Moments in the hunt may be very emotional and the climax of a hunter's life-long dream. All of these factors lead to a perfect opportunity for the hunter to become ill or injured, with the results documented in this study.

Northwestern Colorado is lightly populated. The Memorial Hospital (TMH) in Craig, CO, is the only hospital in Moffat County, the second largest county in the state. The neighboring primary-care health facilities are 50 to 120 miles distant. The nearest tertiary care hospital is 150 miles away. The Memorial Hospital treats about 5000 patients per year in its emergency department (ED). Hunters make up less than $2 \%$ of ED patients on an annual basis, but they represent $8 \%$ to $10 \%$ of ED patients during the peak hunting months of October and November.

The Memorial Hospital's service area is about 8000 square miles, consisting of alpine, foothill, sagebrush, and desert canyon habitats. Small game hunting is not prominent in the service area, while hunting for mule deer, elk, and pronghorn antelope is very popular. For purposes of this study, all hunters seen were considered to be big game hunters.

\section{Methods}

Patients admitted to the TMH ED were asked if they were hunting at the time of their illness or injury. The registration clerk was primarily responsible for flagging the hand-written log book if the response was positive. The ED nurse, upon taking a history, may have identified some of the patients as hunters. The ED was single staffed by an on-call local private-practice family or internal medicine physician. The log book data were compiled at the end of each month and at the end of each hunting season. Data included patient name, state of residence, and discharge diagnosis.

Additional mortality data were obtained from the Moffat County coroner's office. The estimated number of hunters and total hunting days in the study area were provided by the Colorado Division of Wildlife. National statistics from the National Ski Areas Association were used to compare hunter vs skier ED visits. National injury data for swimmers and bicyclists were obtained from the National Safety Council.

\section{Results}

There were 725 ED visits by hunters during the 9 years of the study, yielding an average of 80 visits per year.
Hunter visits ranged from 48 to 103 per year, with no notable trend in annual ED visits during the 9-year study period (Table 1).

\section{INJURIES}

Trauma was identified in 327 , or $45 \%$, of the patient visits. There were 155 lacerations, at least 113 of which were the result of knife injuries. In 2002 the 20 lacerations were not detailed with regard to the inflicting instrument. Most of the knife injuries were to the left hand or forearm. Hunters typically reported that they were field dressing or skinning a carcass and "slipped." Others reported that both hands were deep in the entrails when the left hand came into contact with the sharp blade. Unique lacerations attributable to the rifle scope striking the eyebrow and/or nose upon firing were seen several times in hunters. Additionally, hunters arrived in the ED with puncture wounds to the buttocks, the perianal region, and the posterior thighs as a result of falling on their trophy antlers. Sprains $(60,8 \%)$, contusions (18, $2 \%)$, and burns $(5,<1 \%)$ were also noted, without an apparent trending change in terms of frequency. Horserelated injuries declined during the study period, most likely as a result of the decreasing use of horses for big game hunting. In the first 4 years of the study, 15 fractures were reported to have resulted from interaction with horses, while in the most recent 4 years, just 2 fractures were related to the use of horses. All-terrain vehicle (ATV) use increased markedly during the study period. ${ }^{1}$ Combined ATV and other motor vehicle injuries increased from 21 in the first 4 years of the study to 25 in the most recent 4 years. Gunshot wounds (GSWs) accounted for $4(<1 \%)$ of the ED visits.

\section{ILLNESSES}

Medical illnesses accounted for 31\% (229) of ED visits by hunters. Nearly half (105) were seen in the ED for possible cardiac symptoms, including chest pain, shortness of breath, and edema. Seventy-five of the visits (10\%) were for flu-like symptoms. A variety of other illnesses accounted for 49 visits (7\%).

\section{MISCELLANEOUS VISITS}

The remaining 169 ED visits (24\%) were labeled "other" or miscellaneous and could not be clearly identified as medical or traumatic visits. Examples of these included visits for back pain, headache, insect bites, and hypothermia. 
Table 1. Injuries and illnesses in big game hunters presenting to the Memorial Hospital Emergency Department, Craig, CO, from 1997 to 2005

\begin{tabular}{|c|c|c|c|c|c|c|c|c|c|c|c|}
\hline & 1997 & 1998 & 1999 & 2000 & 2001 & 2002 & 2003 & 2004 & 2005 & Total & $\begin{array}{c}\text { \% of Grand } \\
\text { total }\end{array}$ \\
\hline \multicolumn{12}{|l|}{ Trauma visits } \\
\hline Lacerations (due to knives) & $17(16)$ & 17 (14) & $21(20)$ & $16(14)$ & $14(8)$ & $20 *$ & $6(5)$ & $22(17)$ & $22(19)$ & $155(113)$ & $21(16)$ \\
\hline Sprains & 9 & 9 & 13 & 11 & 0 & 3 & 4 & 6 & 5 & 60 & 8 \\
\hline MVA/ATV $\dagger$ & 11 & 6 & 1 & 3 & 3 & 4 & 5 & 6 & 10 & 49 & 7 \\
\hline Fractures (horse related) & $5(2)$ & $8(4)$ & $10(6)$ & $5(3)$ & $2(2)$ & 2 & 0 & $4(2)$ & 0 & $36(21)$ & $5(3)$ \\
\hline Contusions & 4 & 0 & 1 & 0 & 2 & 0 & 2 & 2 & 7 & 18 & 2 \\
\hline Burns & 0 & 0 & 0 & 0 & 3 & 0 & 0 & 1 & 1 & 5 & $<1$ \\
\hline Gunshot wounds & 0 & 1 & 1 & 0 & 0 & 1 & 1 & 0 & 0 & 4 & $<1$ \\
\hline Total trauma visits & 46 & 41 & 47 & 35 & 24 & 30 & 18 & 41 & 45 & 327 & 45 \\
\hline \multicolumn{12}{|l|}{ Medical visits } \\
\hline Cardiac (deaths) & 12 & $13(1)$ & $12(1)$ & $13(2)$ & 10 & 9 & 6 & 12 & 18 & $105(4)$ & $14(4)$ \\
\hline Flu-like symptoms & 9 & 9 & 19 & 8 & 4 & 4 & 2 & 9 & 11 & 75 & 10 \\
\hline Other medical & 0 & 0 & 0 & 0 & 0 & 0 & 20 & 14 & 15 & 49 & 7 \\
\hline Total medical visits & 21 & 22 & 31 & 21 & 14 & 13 & 28 & 35 & 44 & 229 & 31 \\
\hline \multicolumn{12}{|l|}{ Other visits } \\
\hline Headache, back strain, insect bites & 30 & 29 & 25 & 14 & 32 & 26 & 2 & 6 & 5 & 169 & 24 \\
\hline Total ED visits & 97 & 92 & 103 & 70 & 70 & 69 & 48 & 82 & 94 & 725 & $100 \ddagger$ \\
\hline
\end{tabular}

*In 2002 knife injuries were not broken out.

$\dagger$ MVA indicates motor vehicle accident; ATV, all-terrain vehicle.

$\doteqdot$ May not equal $100 \%$ as a result of rounding.

Note: Numbers in parentheses correspond to words (knives, horse related, deaths) in parentheses in the far left column. 
Table 2. Comparison of trauma-related fatalities due to outdoor recreational activities

\begin{tabular}{lccc}
\hline & Annual & Per million days & Per million participants \\
\hline Hunting & & & \\
$\quad$ Northwest Colorado (1997-2005) & 0.11 & 0.43 & 1.6 \\
$\quad$ Colorado (2004) & 2 & 1.03 & 3.5 \\
$\quad$ United States (2004) & 31 & 0.12 & 2.0 \\
Skiing, United States (2004) & 45 & 0.80 & 3.5 \\
Swimming, United States (2003) $^{6}$ & 3300 & 0.33 & 1.1 \\
Bicycling, United States (2003) $^{6}$ & 700 & 1.06 & 19 \\
\hline
\end{tabular}

\section{FATALITIES}

Four hunters were pronounced dead in the ED. All were determined to have died of cardiac causes. An additional 5 hunter deaths were reported during the study period by the Moffat County coroner's office. Three of these were pronounced dead in the field as a result of cardiac causes, 1 death resulted from an accidental self-inflicted GSW to the head, and 1 death was motor vehicle related.

\section{Discussion}

Northwest Colorado is well known for its large populations of elk, mule deer, and pronghorn antelope. Hunting is a major industry and is economically important to the area. In 2004 the Colorado Division of Wildlife issued 48500 licenses for big game in the TMH service area. $^{3}$ The majority $(33800,70 \%)$ of the licenses were for elk hunting. Deer licenses $(13700,28 \%)$ and pronghorn antelope licenses $(950,2 \%)$ made up the total. Annual numbers of hunters have remained stable over the 9-year study period.

Big game hunting, like other outdoor activities, carries multiple risks. Hunter fatigue and excitement, higher altitude, poor weather, as well as unfamiliarity with guns, knives, and ATVs all likely play a role in hunter ED visits.

\section{TOTAL ED VISITS}

There were about 48500 big game hunters in the TMH service area annually, or 436500 total hunters over the 9 years of study. On average hunters spent 3.7 days hunting, totaling 180000 hunter-days per year, or 1.61 million hunter-days over 9 years. $^{2}$ The incidence of hunters requiring an ED visit was thus calculated to be 1.7 per 1000 . The incidence of an ED visit on a given day of hunting was 0.5 per 1000 hunting days. Comparable statistics for total injury plus illness ED visits of hunters could not be found in the literature.

A report from 2 years of data from a major Colorado ski resort, with a million skier-days per year, indicated 4.1 ED visits for illness and injury per 1000 skier days, an incidence measuring 8 times that of the hunters ( $\mathrm{P}$. Freedman, MD, oral communication, January 15, 2006).

\section{FATALITIES}

Sources of mortality statistics for outdoor activities generally report only trauma deaths directly related to the sport and do not include deaths due to traveling or illnesses. Big game hunting trauma deaths in northwest Colorado were 1.6 per million participants or 0.43 per million hunting days; thus, big game hunting is less risky than skiing or bicycling (Table 2).

A 1990 Montana study reported 27 deaths per million hunters; all deaths were firearm related. ${ }^{7}$ In a Wisconsin study of 125 hunter injuries in a single institution over 4 years (1989-92) there were 2 trauma deaths, one from a GSW and one from a fall from a tree. ${ }^{8}$ No incidence figures were given in the Wisconsin study.

Hunting in Colorado has become a safer activity in recent decades. In the 1960s Colorado averaged 10 fatal firearm-related hunting incidents and 24 nonfatal incidents annually. ${ }^{4}$ In 1970 the state legislature passed laws requiring big game rifle and muzzle-loader hunters to display a minimum of 500 square inches of blaze orange outerwear. All hunters born after 1949 were required to hold a hunter-safety certificate. Loaded firearms in vehicles were forbidden. Injury and fatality rates dropped significantly after these measures were instituted. In the 1990s, hunter firearm fatalities were slightly over 1 fatality annually, and nonfatal firearm injuries measured 11 per year. In 2004 a total of 15 firearm incidents were recorded in Colorado hunters, 2 of which were fatal and 13 of which were nonfatal. Six of the firearm incidents involved big game hunters and 9 involved small game hunters. That same year 560000 hunting licenses were issued in Colorado.

Table 3 shows that 7 of the 9 hunter deaths in the TMH service area during the study period were attri- 
Table 3. Fatalities of big game hunters in northwest Colorado from 1997 through 2005

\begin{tabular}{lc}
\hline \multicolumn{1}{c}{ Type of fatality } & No. of fatalities \\
\hline In hospital & 4 \\
Out of hospital & 5 \\
Total & 9 \\
Cardiac & 7 \\
Gunshot wound & 1 \\
ATV/motor vehicle related* & 1 \\
Total & 9 \\
\hline
\end{tabular}

*ATV indicates all-terrain vehicle.

buted to cardiac causes. Four cardiac deaths occurred in the ED and 3 occurred in the field. There was 1 selfinflicted accidental GSW death and 1 motor vehiclerelated death.

\section{INJURIES}

Injuries due to the improper use of hunting knives (113, $35 \%$ of the injuries) predominated in the data. Modern society allows for infrequent use of knives. A hunting trip may be the only time each year that the injured person has had the opportunity to use his outdoor knife. Unfamiliarity with knives, excitement, inclement weather, poor footing, darkness, and other factors likely contribute to the high incidence of this self-inflicted injury. Most of the reported lacerations were superficial and to the left hand and forearm. These were the findings of the Montana study as well, in which injury to the upper extremity $(51 \%)$ was common and a knife was often the cause (34\%). ${ }^{7}$ In that study, field dressing the game was often the reported activity at the time of injury (36\%).

A unique facial injury was noted occasionally in our study: a curved, sometimes deep laceration over the right eye that often extended to the bridge of the nose. The recoil of a high-powered, telescoped rifle can strike the inexperienced or excited big game hunter with considerable force, resulting in this type of injury.

Another unique injury of big game hunters in our study was caused by the sharp and upturned points of deer or elk antlers. The injury often occurred when the harvested animal, being dragged across a snowy, sloped surface, slid into the hunter, causing the hunter to fall onto the upturned antler tips. Another example involved a hunter seated in the box of a pick-up truck along with his harvested trophy buck or bull. When the vehicle struck a pothole the hunter lurched upward, the carcass slid beneath him, and the hunter came down onto the antler points. These painful and infection-prone puncture wounds were seen in the peri-anal region, scrotum, buttocks, and posterior thighs.

Fractures accounted for 36 ED visits, 21 of these being related to falls from or altercations with a horse. Horse-related fractures declined during the years of the study, probably as a result of a decrease in the use of horses during big game hunts.

A total of $47(7 \%)$ of the ED visits were related to motor vehicle and ATV use. All-terrain vehicle registrations in Colorado more than tripled during the course of the study, to over 100000 in $2005^{1}$; ATV-related injuries increased over the same time period, reflecting the increasing use of ATVs. Injuries were usually reported to be related to excessive speed, steep terrain, or attempts to drag field-dressed animals with the ATV.

Gunshot wounds were relatively uncommon, totaling just $4(0.5 \%)$ in the 9-year period. The GSW injuries were to the foot (2), the subcutaneous area of the arm (1), and superficially to the buttocks (as a result of bullet shrapnel that ricocheted off a car frame; 1). All but the latter GSW were self-inflicted. One of the foot injuries was severe and required tertiary care. The study of hunting injuries in central Wisconsin over 4 years revealed 9 GSWs, none of which were fatal. ${ }^{8}$ The Montana study of hunting injuries over the 1990 hunting season showed 5 of $16(31 \%)$ GSWs to be fatal. ${ }^{7}$

\section{ILLNESS VISITS}

The most common medical ED visits $(105,14 \%)$ were for cardiac symptoms. All 4 of the ED fatalities were cardiac, presumably secondary to acute myocardial infarction. Flu-like symptoms $(75,10 \%)$ were often seen. Other illnesses $(49,7 \%)$ were less common. Medical ED visits have not been studied previously in big game hunters. There were more medical and miscellaneous conditions treated $(398,55 \%)$ than traumatic conditions (327, 45\%).

\section{MISCELLANEOUS VISITS}

Some of the ED visits $(169,24 \%)$ could not be clearly defined as either medical or traumatic visits. Examples include patients arriving at the ED with headache, low back pain, insect bites, and hypothermia.

\section{LIMITATIONS OF THE STUDY}

We probably did not identify all injured and ill hunters in the service area over the study period. Some hunters could have, and probably did, visit the ED without announcing themselves as hunters. Some ill or injured hunters may have sought treatment in private medical 
offices in the community. We did not survey local medical clinics formally, although local physicians stated that few hunters were seen in their private offices. Other hunters probably returned to their home city prior to seeking treatment for illness or injury. Alcohol use was not considered in this study, although it was generally felt that alcohol seldom played a role in a hunter's ED visit. The Wisconsin study reported that 3 of the $125 \mathrm{ED}$ visits were alcohol related. A few of our ED patients were transported to tertiary hospitals and were thus lost to follow-up. No fatalities in this group were identified in the study.

\section{PREVENTION OF HUNTER ILLNESSES AND INJURIES}

The data presented indicate significant morbidity and mortality of big game hunters from cardiac diseases. This indicates that prospective hunters and their health care advisors should consider a prehunt evaluation some months prior to the planned trip to identify, modify, and treat cardiac risk factors. Hunters in this study were much more likely to die from a heart condition than from any other cause.

All-terrain vehicle use has increased, as have injuries related to their use. No formal training is required for ATV driving. Mountain terrain and weather conditions can make for very hazardous off-road driving, even for those with flat-land experience. Formal training in safe ATV operation should be encouraged or required.

Knife injures were very common in this study, as they have been in other studies of hunting accidents. Hunter safety courses are offered in all 50 states and have been very successful, especially in Colorado, in reducing hunting accidents. ${ }^{3}$ Hunter safety instructors could consider a unit in safe knife handling and practical training on field dressing of game animals.

Gunshot wounds among big game hunters are, fortunately, infrequent. However, vigilance in safe gun handling is an axiom of hunting and should never be minimized.

\section{Conclusion}

Big game hunters in western Colorado were treated in an ED for a wide variety of medical, traumatic, and miscellaneous conditions. The incidence of hunter ED visits was lower than that of skiers, and the incidence of hunter injuries and deaths was comparable to those of bicyclists and swimmers.

Knife injuries in hunters were frequent. Emergency department visits for possible cardiac diseases were also noted frequently. Deaths among hunters are most commonly caused by cardiac factors. Gunshot wounds are infrequent. Prehunt cardiac evaluations are suggested, as is additional training in the use of knives and ATVs.

\section{Acknowledgments}

Thanks to Marie Kettle, RN, for data collection and to Lu Tarr and Tom Beachman for manuscript assistance.

\section{References}

1. Hale T. Colorado State Parks. Available at: http://www. parks.state.co.us/home/publications/Fact_Sheets/2005. Accessed January 30, 2006.

2. Colorado Division of Wildlife. Hunting is safe in Colorado. Available at: http://www.wildlife.state.co.us/Hunting/ BigGame/StatisticsRecap. Accessed January 30, 2006.

3. Cousins M. Colorado hunter education program. Available at: http://www.wildlife.state.co.us/Hunting/HunterEducation/ IncidentReports. Accessed January 30, 2006.

4. International Hunter Education Association. 2004 Hunter incident safety report. Available at: http://www.ihea.com/ news/detail. Accessed August 15, 2006.

5. National Ski Area Association. Facts about skiing/snowboard safety. Available at: http://www.nsaa.org/nsaa/press/ 0506. Accessed August 15, 2006.

6. National Safety Council. Injury facts 2003. Available at: http://www.nsc.org/lrs/statinfo. Accessed August 15, 2006.

7. Lambrecht CJ, Hargarten SW. Hunting-related injuries and deaths in Montana: the scope of the problem and framework for prevention. J Wilderness Med. 1993;4:175-182.

8. Stueland D, Carpenter WS, Cleveland D. Summary of hunting injuries in central Wisconsin: a 4-year experience at a rural referral center. Wilderness Environ Med. 1995;6:196202. 